\title{
Using Session-RPE to Monitor Training Load in Swimmers
}

Lee Wallace, Aaron Coutts, PhD, Jon Bell, Narelle Simpson, and Katie Slattery School of Leisure, Sport and Tourism, University of Technology, Sydney, Australia

\section{S U M M A R Y}

THE ABILITY TO MEASURE AND
CONTROL THE INTERNAL TRAIN-
ING LOAD (TL) OF ATHLETES IS
IMPORTANT TO OPTIMIZE ATH-
LETIC PERFORMANCE. HOWEVER,
AT PRESENT, THERE ARE NO
METHODS AVAILABLE FOR EVAL-
UATING INTERNAL TL DURING
SWIMMING. THE SESSION-RPE
METHOD IS A PRACTICAL, NON-
INVASIVE SYSTEM USED TO
QUANTIFY THE INTERNAL TL
PLACED ON ATHLETES. THIS ARTI-
CLE DISCUSSES HOW THE SES-
SION-RPE METHOD MAY BE USED
TO MONITOR SWIM TRAINING AND
ULTIMATELY IMPROVE THE TRAIN-
ING PROCESS OF SWIMMERS.

\section{INTRODUCTION}

he ability for coaches to titrate increases in physical training loads (TLs) with appropriate recovery is of critical importance for optimizing athletic performance (18). However, despite increases in coach education and an increasing focus on well-designed, evidence-based training programs, there still remains a relatively high occurrence of injury, illness, and undesired competition outcomes in athletes (17). It has been widely recognized that accurate monitoring of TL may improve an athlete's preparation for competition. However, in sports such as swimming, few simple methods are available for coaches to monitor the physical TL of their competitive swimmers.

Many swim coaches rely on their previous experience, intuition, and perception of how hard an athlete is training when determining the amount of physical training that should be undertaken by each athlete. However, because of the complexity of interactions between the components that make up a swimming program (e.g., endurance, technique, speed, and strength), a coach's perception and intuition may not be the most reliable method for accurately monitoring physical TL. Therefore, the major difficulty lies in establishing the training stress imposed on the athlete by each component of the training program.

\section{CURRENT METHODS}

There are a variety of methods available to coaches for monitoring physical TL in athletes. Typically, the majority of coaches prescribe training programs in terms of an external TL. External TL is defined as the work completed by an athlete (i.e., distance swum) and is measured independently of their internal characteristics (i.e., their physiology). For example, in swimming, coaches often prescribe training based on distance and/or time (eg. $10 \times 100$ $\mathrm{m}$ at 1:40 min:s holding 1:05 min:s). However, it is the relative physiological stress imposed on the athlete (internal TL) and not the external TL completed by the athlete that determines the stimulus for training adaptation (19). An example of the same session using a measure of internal TL may read $10 \times 100 \mathrm{~m}$ on 1:40 min:s holding $\sim 90 \%$ HRmax. It is widely recognized that the physical stress imposed on an athlete during each session is related to both the volume and the intensity of the exercise bout. In swimming, it is difficult to accurately measure the stress imposed on a swimmer during training using traditional measures such as HR.

The most widely accepted methods for evaluating internal training intensity in endurance athletes uses heart rate (HR) as a measure of exercise intensity $(1,7,13,16)$. However, using $\mathrm{HR}$ to measure exercise intensity in swimming has several limitations. For example, the HR response is a relatively poor method for evaluating intensity during high-intensity exercise such as weight, interval, and plyometric training (9). These types of highintensity training sessions are common in a typical swim program. In addition, we have found that the likelihood of technical failure when using traditional HR monitoring methods in an aquatic environment is increased. Because of these limitations, we suggest that there is a need for an alternative method that is simple, valid, and reliable for quantifying training loads in swimmers.

KEY WORDS:

periodization; swimming; monitoring training; quantifying training; aquatic exercise

Copyright (C) National Strength and Conditioning Association. Unauthorized reproduction of this article is prohibited. 


\section{THE SESSION-RPE METHOD}

The session-RPE method is a simple system for monitoring internal TL in athletes. This system requires athletes to subjectively rate the intensity of the entire training session using a rating of perceived exertion (RPE) according to the category ratio scale (CR 10-scale) of Borg et al. (2) (Table 1). After each training bout, the athlete is asked a simple question, such as "How hard was your workout?" The athlete then indicates the intensity of the training session by referring to a numerical value according to the RPE scale. This intensity value is then multiplied by the total duration (minutes) of the training session to create a single measure of internal TL in arbitrary units. To ensure the athletes report a global RPE for the entire training session, the RPE is taken 30 minutes after the completion of the session. We have presented an example of how to calculate internal TL using this method in Table 2.

Previous authors have used psychometric tools such as RPE and the Profile of Mood States to monitor training in swimmers (10-12). However, to our knowledge, no authors have used the session-RPE method to quantify $\mathrm{TL}$ in swimmers. A major

\begin{tabular}{|l|c|}
\hline \multicolumn{1}{|c|}{$\begin{array}{c}\text { Table } \mathbf{1} \\
\text { The 10-point rating of perceived } \\
\text { exertion scale (2) }\end{array}$} \\
\hline Rating & \multicolumn{1}{|c|}{ Description } \\
\hline 0 & Very, very easy \\
\hline 1 & Easy \\
\hline 2 & Moderate \\
\hline 3 & Somewhat hard \\
\hline 4 & Hard \\
\hline 5 & \\
\hline 6 & Very hard \\
\hline 7 & \\
\hline 8 & \\
\hline 9 & \\
\hline 10 & Maximal \\
\hline
\end{tabular}

Table 2

Example of calculating internal training load with session-RPE

Internal $\mathrm{TL}=$ session-RPE $\times$ duration (minutes)

If an athlete indicated that an exercise bout lasting 60 minutes was hard (RPE $=5)$ the internal TL for that session could be determined using the following calculation

Internal $\mathrm{TL}=5 \times 60=300 \mathrm{AU}$

$\mathrm{AU}=$ arbitrary units; $\mathrm{RPE}=$ rate of perceived exertion; $\mathrm{TL}=$ training loads.

advantage of quantifying training load using session-RPE compared with other reported methods is that it is simple and relatively easy to interpret. Furthermore, studies have shown session-RPE to compare favorably with more complicated methods of quantifying training load in endurance (9), team sports $(4,12)$, and resistancetrained athletes (5). On the basis of the collective research, it appears sessionRPE may provide a suitable method for evaluating internal TL in swimming; however, at present, there are few data available to support this suggestion.

Recently, we examined the usefulness of using session-RPE for quantifying internal TL in swimmers during a 4-month training period (20). During this study, more than 160 individual swim training sessions were examined. We found a significant correlation between session-RPE and commonly used heart rate methods (e.g., Banister's TRIMP $[\mathrm{r}=0.74 \pm 0.15]$, Edward's TRIMP $[r=0.75 \pm 0.15]$, and the LT Zone method $[r=0.77 \pm 0.13])(p<$ $0.01)$ for quantifying internal $\mathrm{TL}$ $(7,13,16)$. However, the correlations between session-RPE and HR-based methods were slightly lower than those reported in previous investigations in endurance-based athletes $(r=$ 0.75-0.90) (8).

These findings may be attributed to differences in training methods undertaken by competitive swimmers. For example, a large percentage of swim training is prescribed by coaches in the form of interval-based workouts. Interval training has been associated with an increased reliance on anaerobic energy contribution compared with steady-state exercise (6). Therefore, because HR have previously been shown to be poorly related to highintensity exercise, this may explain the reduced strength between the $\mathrm{HR}$ and RPE methods observed in this study. Our results also showed that sessionRPE to be only moderately related to distance measures for quantifying physical TL $(r=0.65 \pm 0.20, p<$ $0.01)$. This result was somewhat expected, because distance measures taken independently do not take into account the total stress of exercise. For example, it would be far less stressful for a swimmer to perform $10 \times 100 \mathrm{~m}$ at an aerobic intensity than it would for the same swimmer to perform $10 \times$ $100 \mathrm{~m}$ at maximal intensity.

We have also recently investigated the ability for the athletes to perform each training session at the load intended by the coach (20). This was achieved by comparing the coaches estimated duration and RPE measures after each exercise bout with the values reported by the athletes. Our findings reveal significant differences in the athlete's subjective measures of training intensity compared with coach estimations $(p<0.003)$. Interestingly, the athletes tended to report greater intensities during sessions designed to be easy $(\mathrm{RPE} \leq 2)$ and reduced intensities during sessions designed to be hard $(\mathrm{RPE} \geq 5)$. These results demonstrate a lack of communication between athletes and coach and a poor control of training variables placing athletes at an increased risk of maladaptive training. This observation provided important feedback to the coach that was then used to modify the training practices of their swimmers (i.e., closer 
attention was paid to providing appropriate motivation and instructions to their swimmers during training sessions).

\section{PRACTICAL APPLICATIONS}

To achieve successful swimming performances, athletes must complete periods of intense physical training interspersed with appropriate recovery periods. Typically, a swimming program involves a combination of interval training, steady-state training, and dry-land training. Previously, it has been difficult to quantify the internal training stress from the variety of training modalities and compare them on a common scale. Fortunately, the session-RPE method provides a simple, noninvasive method for quantifying and comparing internal TL in a wide range of exercise conditions. We have listed below the advantages of implementing session-RPE for quantifying physical TL in swimmers.

\section{SUMMATING TRAINING COMPONENTS TO CALCULATE OVERALL INTERNAL TL}

A typical swimming program consists of a variety of different exercise stimulus (e.g., steady-state, interval, and dry-land training). The sessionRPE system allows coaches to evaluate and compare the training stress imposed on individual athletes during each component of the training program. Figure 1 demonstrates how individual components of a typical swim program can easily be summated to show the effects of each component on the total internal TL.

\section{DETERMINING WHETHER \\ ATHLETES PERFORM TLS PRESCRIBED BY THE COACH}

Our findings, supported by other research (10), show that athletes frequently undertake training sessions at an intensity that is different to the intensity prescribed by the coach. It appears athletes often train too hard during recovery sessions, which inhibits their ability to obtain the desired intensity during more difficult training sessions. The session-RPE method may provide coaches with a method for monitoring

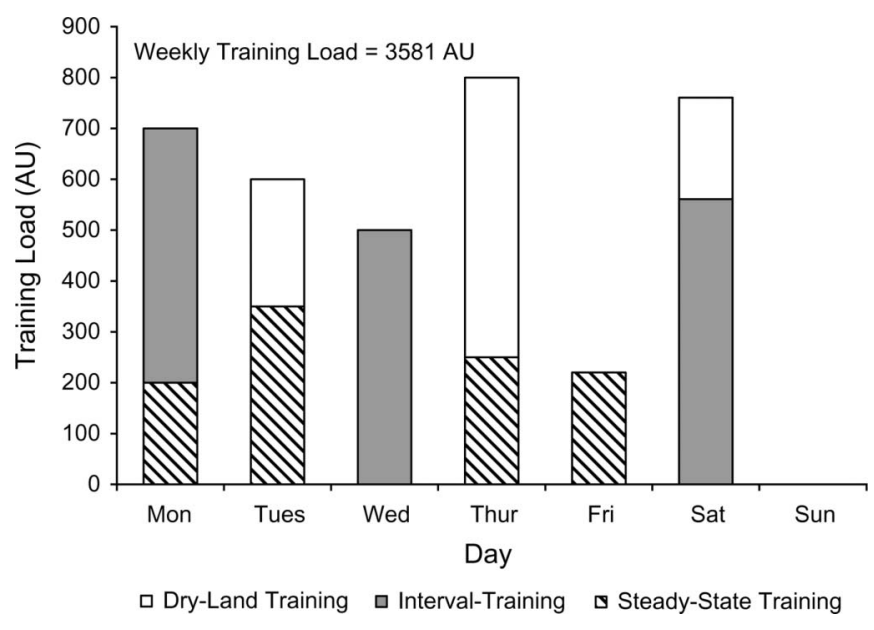

Figure 1. Summating training components to show overall internal TL. the intensity of each training session, ensuring increased intensity during high-intensity workouts coupled with improved recovery periods. Figure 2 shows a graphical representation of the pitfalls associated with athlete training intensity compared with the intensity prescribed by the coach.

\section{IMPROVING PERIODIZATION STRATEGIES}

A decrease in the day-to-day variability in training load (i.e., alternated hardday, easy-day training) may increase the incidence of illness in athletes (8) and have a negative impact on performance (3). For example, Bruin et al. (3) observed reduced running performance in race horses where "easy" days were increased in a program that combined easy and hard training days. At present, there are few studies to support these findings; however, it does appear that a decrease in day-to-day training variability, together with an increase in overall training load, may contribute to negative training effects in athletes.

The session-RPE training monitoring system provides a simple method for quantifying the training dose of each exercise bout. This information can easily be graphed with a spreadsheet software program (e.g., Microsoft Excel) or through specific on-line training diaries (e.g., www.trainingload.com) to ensure appropriate day-to-day variability between training sessions is met. An example of how this can be done is shown in Figure 3, which shows how session-RPE can be used to improve

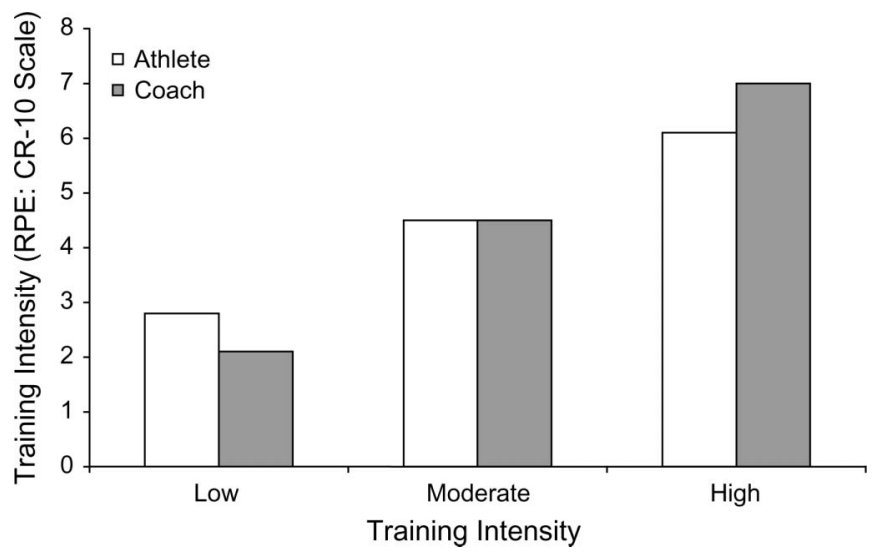

Figure 2. A graphical representation of the mismatch in training intensity which may occur between athlete and coach. 


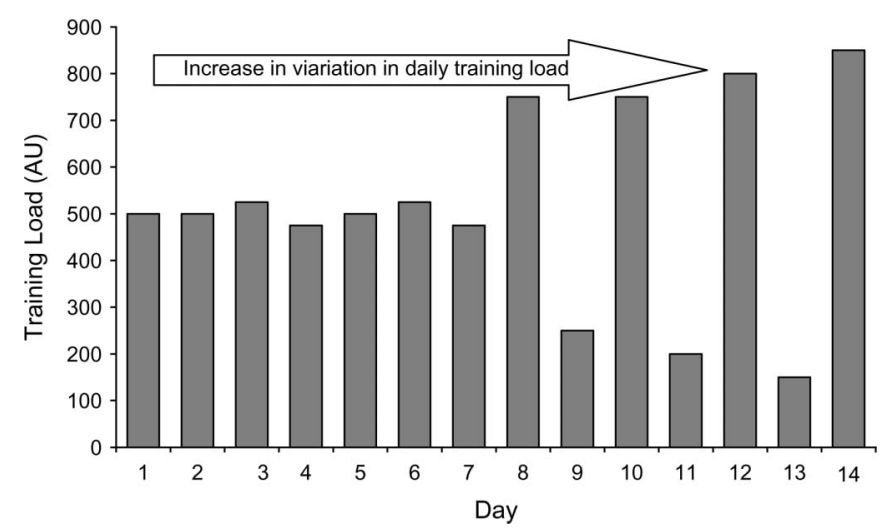

Figure 3. Example of how training loads can be modified to improve the variation in day-to-day training load.

training load placement with no change in overall training load between the first and last 7 days.

\section{MONITORING INDIVIDUAL TRAINING LOADS}

The ability for athletes to adapt to increasing training loads is largely an individual process (19). Inappropriate increases in training load with inadequate recovery have previously been linked to increases in the incidence of illness (10) and with a negative impact on performance (3). Swimming training usually is completed in a squad environment in which similar training stimulus is prescribed to a group of individuals. Therefore, for a given exercise bout, some athletes would perceive the workout to be more stressful than others placing them at an increased risk of maladaptive training. Session-RPE allows coaches to closely monitor the internal TL of each athlete and more clearly identify athletes who are coping or not coping to the set external training loads.

\section{MONITORING TRAINING LOADS AFTER A BREAK FROM REGULAR TRAINING}

Often athletes will ignore the effects of reduced fitness and strength after a prolonged break from regular training. The session-RPE training monitoring system allows coaches to prescribe appropriate loads and avoid the negative effects of returning to regular training loads too rapidly.

\section{SUMMARY}

To obtain optimal performance in competitive swimming, athletes must undertake periods of heavy training loads interspersed with appropriate recovery periods. Unfortunately, until now, swim coaches have not been able to accurately measure the internal TL undertaken by their swimmers. The session-RPE training monitoring system may be a useful tool for swimming coaches to monitor internal TL in athletes. This method can be used to provide coaches and athletes with instant feedback regarding the internal training stress imposed on an athlete from each exercise bout. This information can then be used to improve periodization strategies, improve session execution and ultimately improve swimming performance.

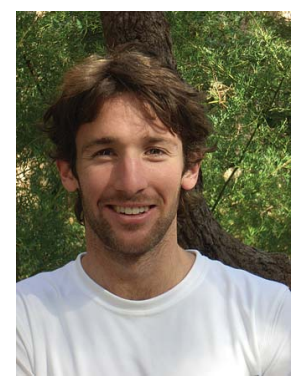

Lee Wallace is a PhD Candidate at the University of Technology, Sydney.

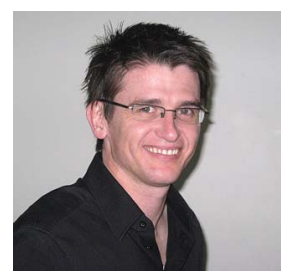

Aaron Coutts is a Senior Lecturer in Sport and Exercise Science at the School of Leisure, Sport, and Tourism within the University of Technology, Sydney.

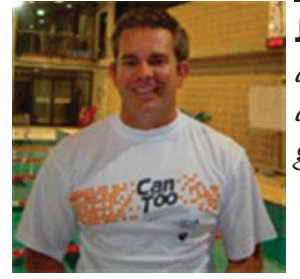

Jon Bell is the aquatics manager at Montie Sant Angelo Girls School.

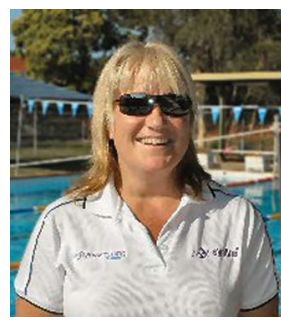

Narelle Simpson is the owner and Head Coach of the Narelle Simpson Swim School, Sydney, Austratia.

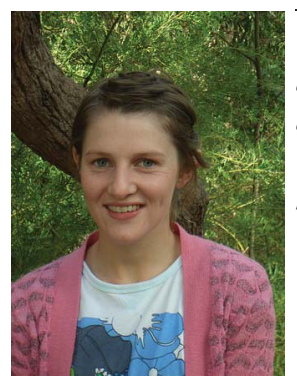

Katie Slattery is a Sports Scientist at the New South Wales Institute of Sport.

\section{REFERENCES}

1. Banister EW. A systems model of training for athletic performance. Aus J Sports Med Exerc Sci 7: 57-61, 1975.

2. Borg GAV, Hassmen $P$, and Langerstrom M. Perceived exertion in relation to heart rate and blood lactate during arm and leg exercise. Eur J Appl Physiol 65: 679-685, 1985.

3. Bruin G. Adaptation and overtraining in horses subjected to increasing training loads. J Appl Physiol 76: 1908-1913, 1994.

4. Coutts AJ. Validity of the session-RPE method for determining training load in team sport athletes. J Sci Med Sport 6: 525, 2003.

5. Day M. Monitoring exercise intensity during resistance training using the session-RPE scale. J Strength Cond Res 18: 353-358, 2004. 
6. Drust B, Reilly $\mathrm{T}$, and Cable NT. Physiological responses to laboratorybased soccer-specific intermittent and continuous exercise. J Sports Sci 18: 885-892, 2000.

7. Edwards S. High performance training and racing. In: The Heart Rate Monitor Book. S. Edwards, ed. Sacramento, CA: Feet Fleet Press, 1993. pp. 113-123.

8. Foster $\mathrm{C}$. Monitoring training in athletes with reference to overtraining syndrome. Med Sci Sports Exerc 30: 1164-1168, 1998.

9. Foster C, Florhaug JA, and Franklin J. A new approach to monitoring exercise training. J Strength Cond Res 15: 109115, 2001.

10. Foster C, Heimann KM, Esten PL, Brice G, and Porcari JP. Differences in perceptions of training by coaches and athletes. $S$ Afr $J$ Sports Med 8: 3-7, 2001.
11. Hooper SL. Markers for monitoring overtraining and recovery. Med Sci Sports Exerc 27: 106-112, 1995.

12. Impellizzeri FM. The use of RPE-based training load in soccer. Med Sci Sports Exerc 36: 1042-1047, 2004.

13. Lucía A. Tour de France versus Vuelta a Espana: Which is harder? Med Sci Sports Exerc 35: 872-878, 2003.

14. Morgan WP, Brown DR, Raglin JS, O'Connor PJ, and Ellickson KA. Psychological monitoring of overtraining and staleness. $\mathrm{Br} J$ Sports Med 21: 107-114, 1987.

15. Morgan WP, Costill DL, Flynn MG, Raglin JS, and O'Connor PJ. Mood disturbance following increased training in swimmers. Med Sci Sports Exerc 20: 408-414, 1998

16. Morton RH, Fitz-Clarke JR, and Banister EW. Modeling human performance in running. J Appl Physiol 69: 1171-1177, 1990.

17. Pyne DB, Hopkins WG, Batterham AM, Gleeson M, and Fricker PA. Characterising the individual performance responses to mild illness in international swimmers. $\mathrm{Br} J$ Sports Med 39: 752-756, 2005.

18. Smith DJ. A framework for understanding the training process leading to elite performance. Sports Med 33: 1103-1126, 2003.

19. Viru A and Viru M. Nature of training effects. In: Exercise and Sport Science. W. E. Garrett and D.T. Kirkendall, eds. Philadelphia: Lippincott Williams and Wilkins, 2000. pp. 67-95.

20. Wallace L, Slattery KM, and Coutts AJ. The ecological validity and application of the session-RPE method for quantifying training loads in swimming. J Strength Cond Res, November 8, 2008 [Epub ahead of print].

\section{NSCA PRODUCTS}

Sweatshirt • Item \#SS-000

Stay warm with this comfortable cotton, crew neck sweatshirt with NSCA logo embroidered on left chest and right wrist.

Sizes: $S$ - XXXL* Color: Black Logos: NSCA

Member Price: \$24.99 Non-Member Price: \$32.00

*Sizes XXL and XXXL will accrue $a \$ 2.00$ sizing fee for non-members

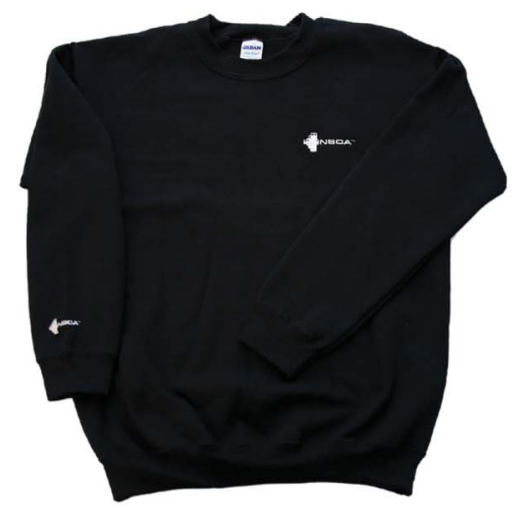

Grey \& Black Beanie • Item \#BH-NSCA-GB

Pink \& Black Beanie • Item \#BH-NSCA-PB

$100 \%$ Acrylic Knit 8" Reversible Beanie with 1 1/2" Trim

Size: One Size Fits Most Logo: NSCA

Color: Grey w/Black trim OR Pink w/Black trim

Member Price: \$9.99 Non-Member Price: $\$ 15.00$

To order...

www.nsca-lift.org・ 800-815-6826

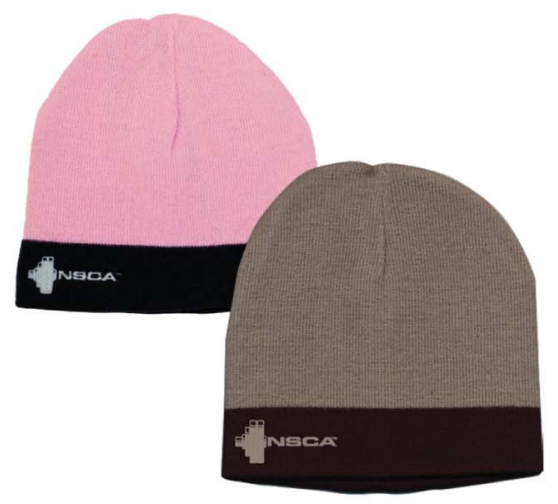

Copyright $($ ) National Strength and Conditioning Association. Unauthorized reproduction of this article is prohibited. 